ANO 10 • NÚMERO $19 \cdot 2$ 2os 2013 • ORGANICOM
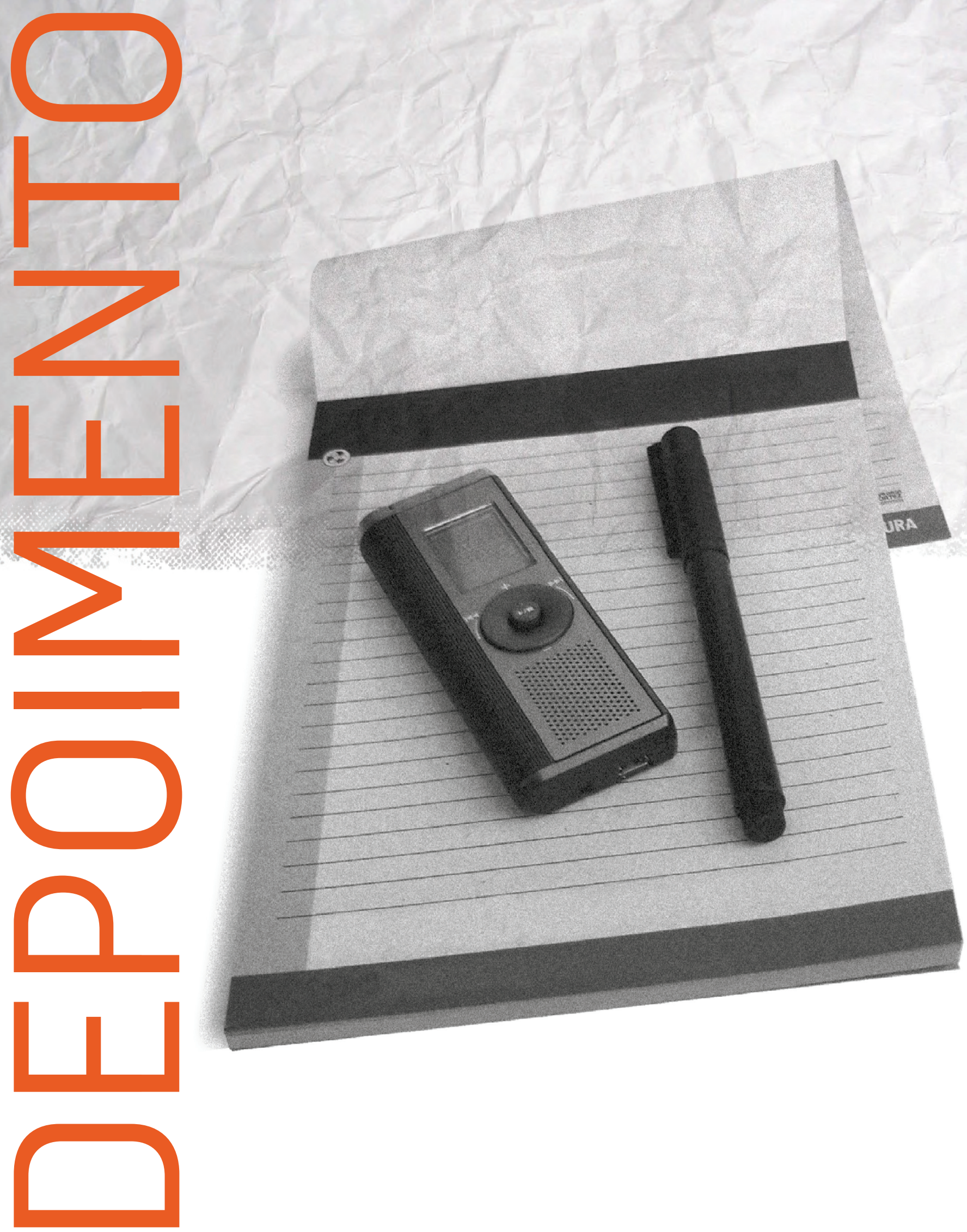


\title{
Infinitas possibilidades com 0 segredo do tempero local
}

\author{
Endless possibilities with the \\ secret of local flavor
}

\section{Posibilidades infinitas con el secreto del sazón local}

\section{Hélio Muniz'}

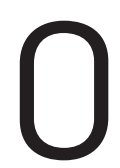

mundo mudou. E a comunicação também. Textos em jornal, que eram produzidos por repórteres em cópias com ajuda de papel carbono para editores, hoje saem do computador diretamente para a gráfica. Eu mesmo sou prova da evolução: já entreguei releases em redações, algo impensável nos dias de hoje. Ainda bem que surgiram os aparelhos de fax e hoje temos e-mail. Hoje, olhamos essas máquinas impressionantes da década de 1980 como crianças atônitas no museu se deparando com réplicas de tiranossauros.

Bilhetes se transformaram em posts nas mídias sociais e a informação se espalhou por milhares de cantos. Todo mundo sabe tudo e todos têm alguma coisa para mostrar ou para conhecer. 0 profissional de comunicação que entra no mercado de trabalho tem mais acesso à informação, mesmo sem comprar um jornal sequer, do que o das três gerações anteriores somadas. É só reparar. Todas as manhãs, de casa para o trabalho, ouvimos, lemos e compartilhamos pelo menos uma dezena de informações, por meio de variados canais - às vezes com um único aparelho.

Isso não significa que há profissionais melhores ou piores conforme as datas de nascimento, que nossos avós eram mais bem informados porque dedicavam horas à leitura de jornais volumosos. Apenas os meios de comunicação estão diferentes e mais rápidos. E, com isso, a forma de pensar a comunicação mudou: a notícia surge nas redes, o profissional vem das redes e não sai delas. Um post em um blog pode causar uma repercussão positiva ou negativa maior do que uma página do jornal o Globo. Simples assim.

1 Carioca, torcedor apaixonado do Flamengo, dividiu sua carreira entre os principais veículos de mídia do país e a comunicação corporativa. Foi repórter de comportamento e cultura do jornal 0 Globo e, durante quase dez anos, subeditor, editor e gerente de produtos de diversas áreas (cultura, tecnologia, economia) do Jornal do Brasil, veículo pelo qual recebeu o mais importante prêmio de jornalismo brasileiro: o Esso, em 1992. Ao fim do século passado, trocou o jornalismo pelas corporações. Foi gerente de Relações Públicas da TV Globo, gerente de Propaganda da AES Eletropaulo, diretor de Conteúdo e Comunicação do iGFinance, portal de internet do Banco Opportunity, sócio-fundador da agência de propaganda Tapioca Comunicação, vencedora de diversos prêmios e diretor de Comunicação e Sustentabilidade da Gol Linhas Aéreas. Atualmente é o diretor de Comunicação do McDonald's no Brasil. E-mail: helio.muniz@br.mcd.com. 
Os próprios veículos de comunicação estão dando esse recado. Redações cada vez mais enxutas, impressos com menos papel, mais versões online. As empresas acompanham. Novos formatos - menos é mais. 0 simples é o diferente.

Como encarar um mundo com pessoas, gerações diferentes? Um mundo de celebridades instantâneas, no qual a cada segundo temos que avaliar o que escrevemos na internet?

Para começar a conversa, precisamos estar receptivos. Só assim podemos entender e acompanhar todas essas mudanças. 0 eixo da comunicação migrou a relevância na direção das mídias sociais. Hoje, o jovem tem a mesma quantidade de hormônio que tínhamos no início da carreira. Mas, com muito mais informação. Ele não liga para a fonte da informação. Por vezes, há mais equívocos por causa dessa certa banalização da credibilidade. Mas, o cenário é esse.

É mandatório entender o caminho das relações. E, na comunicação interna, fica imprescindível saber o que os funcionários esperam da empresa, o que eles querem que a gente fale. Eles querem aprender e não têm paciência. Não gostam de informações confusas - objetividade é uma obrigação óbvia. Eles também gostam de se sentir próximos. Gostam de se reconhecer na empresa, de identificar afinidades com os colegas. Não gostam de superiores inatingíveis. Tampouco aceitam meras promessas, liderança por medo e muito menos fazer a mesma coisa por muito tempo. Rotinas engessadas, nem pensar!

Na verdade, eles querem saber onde estarão daqui a poucos meses. Acham que já viveram muito e estão com menos de trinta anos. Não têm medo de tentar e de errar. Podem ficar por anos ou meses. Aqui cabe uma história pessoal: meu pai trabalhou na Petrobras por trinta anos. Foi seu único emprego. Na época, as oportunidades eram em menor quantidade do que hoje. 0 concurso, o emprego em uma estatal, era mais atraente, mais seguro.

Já eu passei por vários empregos e experiências. Quando me formei, em 1989, trabalhar em estatal estava fora de cogitação - hoje, o cenário mudou e concurso virou "in". Tenho amigos da mesma geração, que, ao contrário, estão há anos em uma empresa, passando por diversos setores, negócios diferentes. Tão apaixonante quanto o que vivenciei. Cada um do seu jeito. E mesmo com todos os blogs e redes, as pessoas ainda continuarão sendo diferentes. Porém, importante: todas elas estarão conectadas.

É um mundo maior e menor simultaneamente. E nós, líderes, precisamos enxergar todas essas variáveis, gerenciar todas as diferenças e estimular - o que, para mim, é uma paixão - os talentos que só esse tipo de gestão traz. Uma vez, ouvi do editor-chefe do Daily Telegraph algo muito esclarecedor. Ele me disse que o melhor diretor de redação não é o sujeito que escreve melhor ou que sabe editar uma matéria. É o que consegue olhar, na frente, para onde o mundo está indo.

E, quando colocamos esse tipo de liderança em prática, o resultado positivo é inevitável. Temos o desafio de mostrar que a experiência não é chata e ultrapassada. Sim, conhecemos toca-discos, fita-cassete, jogamos Atari. Mas acompanhamos todas as evoluções, mudamos a cabeça, transitamos da máquina de escrever para o computador e por isso mesmo somos atraentes para essa nova geração. Não somos afoitos - e, é bom explicar, ser afoito é jovial e representa um começo fundamental - e entendemos que há várias alternativas disponíveis. Somos fãs dos Rolling Stones - e, como eles, construímos o sucesso há décadas.

Engajamento é a palavra. Se o seu colaborador não se vê envolvido na causa da sua empresa, atenção! Ele não vai ficar com você por muito tempo. Se a sua empresa não tem uma causa, um propósito, valores compartilhados e estimulados 
internamente, seu caso é pior ainda. Não vai adiantar investir milhões em ferramentas, canais de comunicação, ouvidorias internas. Tudo isso é extremamente importante. Mas, sem envolvimento, nada feito.

Não precisa de desespero. John Kennedy tem uma ótima recomendação para isso: "o melhor momento para consertar 0 telhado é quando o sol está brilhando".

Quando estou no balcão de um dos mais de setecentos restaurantes McDonald's do Brasil, eu não enxergo um atendente. Estou lidando com um stakeholder da minha companhia. Não tenho a menor pretensão de que ele fique na empresa por anos - se bem que temos o privilégio de contar com vários executivos que fizeram a trajetória do balcão à direção da empresa. Na verdade, meu maior desejo - e o de toda a marca - é que ele se sinta em casa enquanto estiver com a gente. Motivado, suprido das informações necessárias para ser um stakeholder da marca.

Procuramos dar a ele a competitividade que os jovens adoram, sem falar no trabalho em equipe. Premiamos os melhores. Mostramos a ele para onde pode ir e até onde pode chegar. Sei que quando ele descansa ele quer estar conectado. Dou acesso a ele pra isso. Sei que ele gosta de comunicação objetiva e eficiente. No restaurante, são realizadas reuniões. 0 gerente do restaurante, mensalmente, encontra-se com os pais dos funcionários. Também respeitamos e temos muito carinho pelas pessoas com deficiência. E damos o tratamento e a comunicação adequados para eles.

0 desafio: são 50 mil funcionários. Se contabilizarmos o sistema - franqueados e fornecedores -, o número fica muito mais amplo. Sem falar nas distâncias: 23 estados, além da capital federal, mais de 150 cidades. São muitas histórias para ouvir, muitas experiências para compartilhar. Um prato cheio para comunicar.

E é aí que entra o segredo, a cereja do bolo. Igual à receita que a sua mãe não conta para ninguém, porque é de família: o tempero local.

As dimensões culturais brasileiras são um desafio e uma oportunidade. Respeitar as ações regionais faz toda a diferença. Veículos locais têm 100\% de relevância. Conversar com o chefe do Corpo de Bombeiros, com o prefeito. Todos são altamente importantes. São a referência local de uma marca global. 0 banco de confiança, daqueles cuja mensuração é simples: respeito, valor, imagem.

Trato cada gerente de restaurante como um diretor de comunicação. Quem melhor do que ele representa a marca? Em algumas regiões, a milhares de quilômetros do escritório corporativo, ele é o único porta-voz que está lá todos os dias, junto com a sua equipe. Esse gerente, que tem em média vinte e poucos anos, gera um negócio de milhões por ano, comanda um time com dezenas de funcionários, a maioria jovem, a exemplo deste líder.

Esse diretor de comunicação local faz toda a diferença. Ele conversa com o delegado, com instituições do entorno do restaurante, com pais de funcionários. Entende a economia local, o que é importante para a cidade, para a região. Ele é uma mídia local, um veículo importantíssimo para a marca. Junto com seus outros colegas, ele atende diretamente 1,7 milhão de consumidores todos os dias. Um canal privilegiado, que poucas marcas têm: olhar nos olhos dos clientes. E dos funcionários.

Nosso papel é ajudar esses stakeholders, porta-vozes e diretores de comunicação locais, a lidar com todas essas possibilidades. E fazer isso requer zero preconceito. São os nossos principais clientes. E, com todo o respeito que merecem, precisamos compreendê-los. 
Sabendo disso, incentivamos constantemente que eles sejam "bons vizinhos", percebam a comunidade na qual seu restaurante está envolvido, entendam as necessidades locais. Assim seguimos o lema do fundador Ray Kroc - "devolver às comunidades tudo aquilo que recebemos". Uma sabedoria de mais de cinquenta anos e que é tão atual quanto inovações tecnológicas.

Por todas as experiências que vivenciei, a comunicação interna é, sem dúvida, a força, a matriz de tudo. Ela está na base da empresa e atende a todos. Sem ela, a empresa fica sem ouvidos e pode até ter muito a dizer, mas não vai ter com quem falar. Pessoas representam um pilar fundamental. Sem pessoas, não há marca.

Você pode levar anos para construir essa marca. Mas sem seus porta-vozes, com uniformes ou não, sua boa imagem não vai muito longe.

Ousar é preciso. Ser uma metamorfose ambulante. Que sabe o que significa um walkman, mas entende perfeitamente como funciona um ipod. E naturalmente sabe que vai saber entender de muitas outras ferramentas e suas versões. Mais ainda: sem medo, vai aceitar que os colaboradores mais jovens vão aprender muito provavelmente mais rápido do que você.

Já se você tem menos de trinta anos, um convite: converse com seus avós, faça uma busca no Google e conheça de perto um Atari, um aparelho de fax e videocassete. Veja as manchetes dos jornais que não existem mais. Histórico é tudo para um bom comunicador. E informação nunca foi demais.

E, claro, o óbvio nunca deixou de ser relevante: para comunicar é preciso conhecer, ser honesto, reconhecer as fraquezas, identificar as oportunidades. E envolver. 0 papel da comunicação interna é exatamente esse: unir e engajar baby boomers, geração Y, geração Cristal. Um processo vivo, encantador e magnífico. Imperdível! 